\title{
Sensitivity of the hygrothermal behaviour of homogeneous masonry constructions: from Sobol indices to decision trees
}

\author{
Klaas Calle ${ }^{1, *}$, Nathan Van Den Bossche ${ }^{1}$ \\ ${ }^{1}$ Ghent University, Building Physics group, 9000 Ghent, Belgium
}

\begin{abstract}
Historic masonry constructions are difficult to mimic in hygrothermal models. Next to the usual uncertainties on the input of hygrothermal models as the outdoor/indoor climate also the properties of the wall themselves are often highly uncertain due to the natural origin of the aggregates and the various, manual production processes used through time. Therefore, this paper presents a probabilistic analysis that indicates the sensitivity of several damage criteria which are often encountered in practice such as mould growth at the interior surface, frost damage, and potential decay of wooden beam heads. The analysis is based on 1D simulations, including realistic variations on climate parameters as wall properties. With Kriging based surrogate modelling the output of the probabilistic simulations is translated into sensitivity indices, Total Sobol indices. These indices summarize the dependency of the damage criteria for each of the input parameters including multi order effects. The Total Sobol indices indicate a generally high dependency of each of the damage criteria on the rain intensity, the trend of the moisture retention/liquid conductivity curve and the absorption coefficient. Based on the probabilistic output binary flowcharts are generated to indicate for which combinations of input parameters high risks are to be expected. These binary flowcharts can be adopted by e.g. engineering firms to define whether, a more detailed assessment is required, and which input are necessary. This indicates when basic in situ assessments of the hygrothermal properties of the facade can suffice.
\end{abstract}

\section{Introduction}

Historic masonries are produced by humans, in different ways, with different raw materials and on top of this, these ancient constructions have been subjected to diverse climate conditions through time; each of which affected their physical and hygrothermal properties. In practice often large inconsistencies are found as shown by a drilling core of a masonry facade in Fig. 1.

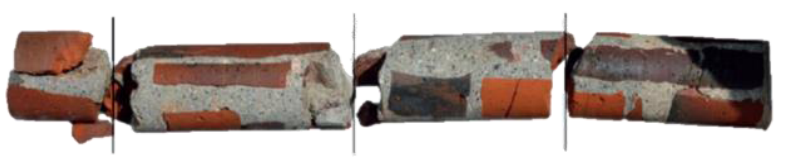

Fig. 1 Drilling core of the Parish church of Deerlijk (18681869), Source: Royal institute for cultural heritage (Belgium)

In the past decade hygrothermal building simulation models have proven to have a great potential in predicting the impact of renovation and restoration strategies on damage of buildings [1]-[3], but the variability on historic masonries hampers the translation from reality to a Heat Air and Moisture (HAM) simulation. Masonries are in models usually abstracted into homogeneous brick constructions to avoid computationally expensive simulations. Therefore, it is important to be aware of their potential inherent uncertainties, when a HAM simulation is performed and the output in interpreted. Unfortunately including this awareness and insights in the analysis of the output of HAM models is not straightforward. The impact of certain deviations on the simulation input parameters is difficult to translate towards the output as multiple physical impacts are possible. For example, an increase of the absorption coefficient $\left(\mathrm{A}_{\mathrm{w}}\right)$ can evidently lead to an increase in the moisture content of the constructions, but as well to a decrease due to the fact that the liquid drying phase of the brick material is highly correlated to the absorption coefficient.

Therefore this paper aspires to gain insight in the impact of variations on the input variables of HAM simulations of historic masonry constructions for realistic variations in practice with original HAM modelling in the Delphin software and surrogate modelling for three predefined output criteria; the number of critical Freeze Thaw Cycles (FTC), the risk on wood decay of a wooden beam head (WD) and the risk on mould growth at the interior surface (MG). First the assumed variations in the input variables for climate and wall are discussed. Secondly a specific method to include the impact of variations on the trend of the moisture retention curve (MRC) and liquid conductivity curve (LCC) of the brick material on the probabilistic simulations process is presented. Thirdly the modelling is performed, and the results are discussed based on Total Sobol indices derived from a Kriging based surrogate model which gives insight in the general dependencies of each of the output criteria in perspective to the input variables. To conclude binary classification

\footnotetext{
${ }^{*}$ Corresponding author: Klaas.Calle@UGent.be
} 
trees are generated to gain more specific insight in de dependencies for combinations of certain input variables.

\section{Input parameters of the simulations}

Table 1 shows that the input parameters for the probabilistic simulations are subdivided in 3 types. The ones linked to the exterior climate, interior climate and the wall properties. The distribution types, based on which the input parameters for the simulations are sampled, are mostly uniform as this is best suitable for a sensitivity analysis. The fixed parameters are expected to have a limited impact based on earlier research or are physically unreasonable to assume as a variable. The categorical parameters are defined for those of the input parameters which have an impact on the simulations but are not suitable as floating variable. The exterior climate is defined by the wall orientation, a location of which a climate Test Reference Year (TRY) is used, a rain exposure coefficient and surface coefficients. The rain exposure coefficient is a coefficient which is multiplied by the horizontal rain defined by the TRY. A uniform variation between 0 and 2 is assumed to include the effect of a potential roof overhang or the potential malfunction of a gutter. The convective heat transfer coefficient and the moisture transfer coefficient are directly linked to each other based on the study of Janssen H. [4]. The variation in the coefficient $\mathrm{c}$ in Table 1 is defined based on Eurocode 1 [5] for realistic variabilities in terrain roughness and orthography. $\mathrm{V}$ represents the wind speed $[\mathrm{m} / \mathrm{s}]$. As for the TRY's included the average wind speed varies between 3 and 5 $\mathrm{m} / \mathrm{s}$ an average convective heat transfer coefficient between 9 and $27.4 \mathrm{~W} / \mathrm{m}^{2} \mathrm{~K}$ is simulated. For the indoor climate conditions there are two possible options adopted in the sampling, a high or a moderate humidity class based on EN 15026 [6]. For the wall properties first the thickness of the wall is defined between realistic boundaries. Constructions over $0.5 \mathrm{~m}$ thick are not included to avoid expensive calculations. The brick type is a categorical parameter which expressed the trend of the MRC and LCC curve and will further be discussed in section 4 . The other hygrothermal material properties which are expected to have a considerable impact on the output criteria are sampled between reasonable ranges based on the building brick category in the IBK database [2]. The sampling is not performed randomly as otherwise unrealistic material properties would be generated. A correlation matrix, derived by Zhao J. (Table 2 in [7]), is used as a sampling condition to avoid unphysical combinations.

Table 1 Input parameters

\begin{tabular}{|l|l|l|}
\hline \multicolumn{1}{|c|}{ Input type } & \multicolumn{1}{|c|}{ Distribution } & \multicolumn{1}{c|}{ Range } \\
\hline Exterior climate & & $1 \rightarrow 360$ \\
\hline Orientation & Uniform & $\begin{array}{l}\text { Essen, Munich, } \\
\text { Bremerhaven }\end{array}$ \\
\hline Climate & Categorical & $\begin{array}{l}\mathrm{h}_{\text {conv }}=9+4^{*} \mathrm{v}^{*} \mathrm{c} \\
\mathrm{c}=0 \rightarrow 1.37 \\
\text { (Eurocode } 1,[5])\end{array}$ \\
\hline $\begin{array}{l}\text { Conv. heat transfer } \\
\text { coefficient }\left[\mathrm{W} / \mathrm{m}^{2} \mathrm{~K}\right]\end{array}$ & Uniform & \\
\hline
\end{tabular}

\begin{tabular}{|c|c|c|}
\hline $\begin{array}{l}\text { Rain exposure } \\
\text { coefficient }\end{array}$ & Uniform & $0 \rightarrow 2$ \\
\hline $\begin{array}{l}\text { Moisture transfer } \\
\text { coefficient }[\mathrm{s} / \mathrm{m}]\end{array}$ & Fixed & $7.7 * 10-9 \mathrm{~h}_{\text {conv }}[4]$ \\
\hline $\begin{array}{l}\text { Solar absorption } \\
\text { coefficient }\end{array}$ & Uniform & $0.4 \rightarrow 0.8$ \\
\hline $\begin{array}{l}\text { Long wave } \\
\text { emissivity }\end{array}$ & Fixed & 0.9 \\
\hline \multicolumn{3}{|l|}{ Interior climate } \\
\hline Interior RH/T & Categorical & $\begin{array}{l}\text { EN } 15026[6], \mathrm{RH} \\
\text { curve A or B }\end{array}$ \\
\hline $\begin{array}{l}\text { Total heat transfer } \\
\text { coefficient inside } \\
{\left[\mathrm{W} / \mathrm{m}^{2} \mathrm{~K}\right]}\end{array}$ & Fixed & 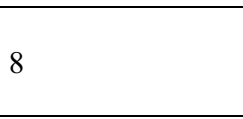 \\
\hline $\begin{array}{l}\text { Exchange } \\
\text { coefficient for } \\
\text { vapour diffusion at } \\
\text { the inside }[\mathrm{s} / \mathrm{m}]\end{array}$ & Fixed & $3 * 10^{\wedge}-8$ \\
\hline \multicolumn{3}{|l|}{ Wall properties } \\
\hline Thickness & Uniform & $0.15 \rightarrow 0.5$ \\
\hline Brick type & Categorical & $\mathrm{C} 1, \mathrm{C} 2, \mathrm{C} 3, \mathrm{C} 4$ \\
\hline$\vartheta_{\text {eff }}$ & $\begin{array}{l}\text { Uniform, } \\
\text { correlated }\end{array}$ & $0.145 \rightarrow 0.425$ \\
\hline$A_{w}$ & $\begin{array}{l}\text { Uniform, } \\
\text { correlated }\end{array}$ & $0.02 \rightarrow 0.83$ \\
\hline$\mu$ & $\begin{array}{l}\text { Uniform, } \\
\text { correlated }\end{array}$ & $6.25 \rightarrow 68.65$ \\
\hline$\lambda$ & $\begin{array}{l}\text { Uniform, } \\
\text { correlated }\end{array}$ & $0.248 \rightarrow 0.654$ \\
\hline $\begin{array}{l}\text { Other material } \\
\text { parameters }\end{array}$ & Fixed & $\begin{array}{l}\text { Based on the } \\
\text { average for the } \\
\text { building brick } \\
\text { category in IBK } \\
\text { database }\end{array}$ \\
\hline
\end{tabular}

\section{Damage criteria}

\subsection{Critical Freeze-thaw cycles}

As a criterion for frost the number of critical Freezethaw-cycles is calculated. When the ice mass volume over the pore volume simulated by the model decreases below $25 \%$ a cycle is assumed. This $25 \%$ criterion is chosen based on the study of Mensinga et al. [8] and based on the fact that a lower criterion, compared to the often assumed $91 \%$, has a more useful output for comparative investigations. In the software the ice volume $\left[\mathrm{m}^{3} / \mathrm{m}^{3}\right]$ is calculated in perspective of the capillary pressure in the pores, freezing point depression is thus considered [9]. As a thermodynamic equilibrium between the ice and the liquid phases leads to an equation describing the capillary pressure of the largest non-frozen pore class as a function of the (negative) temperature. The frozen / unfrozen water content can be calculated. Note that ice formation locally reduces the liquid water content and increases the capillary suction. Thus, a fluid flow is induced towards ice as long as air space in pores is available.

\subsection{Rotting of wooden beam heads}

Lately, a hot topic in HAM-research is the potential rotting of wooden beam heads embedded in masonry 
constructions, especially in perspective of interior insulation [10]-[13]. Research [10] has shown that poor airtightness sealing around the wooden beam heads can significantly increase the risk for wood decay due to exfiltration of moist indoor air. Hence, it is generally accepted that airtight connections are a prerequisite for interior insulation solutions. It is thus assumed that in the simulations no exfiltration occurs at these locations. In the simulations, an indication for the potential risk on wood decay was based on the relative humidity and temperature in the masonry construction at a depth of $120 \mathrm{~mm}$ from the inside $(100 \mathrm{~mm}$ of brick and $20 \mathrm{~mm}$ of plaster) of the wall. The wood decay itself was evaluated by assessing the yearly number of hourly data points that exceed the curve defined in WTA-Merkblad 6-8-15 [14] (Figure 67) over the total number of data points. The ratio of the number of points above the line and the number of hours in a year (8760) gives a normalized value for wood decay risk between 0 and 1 .

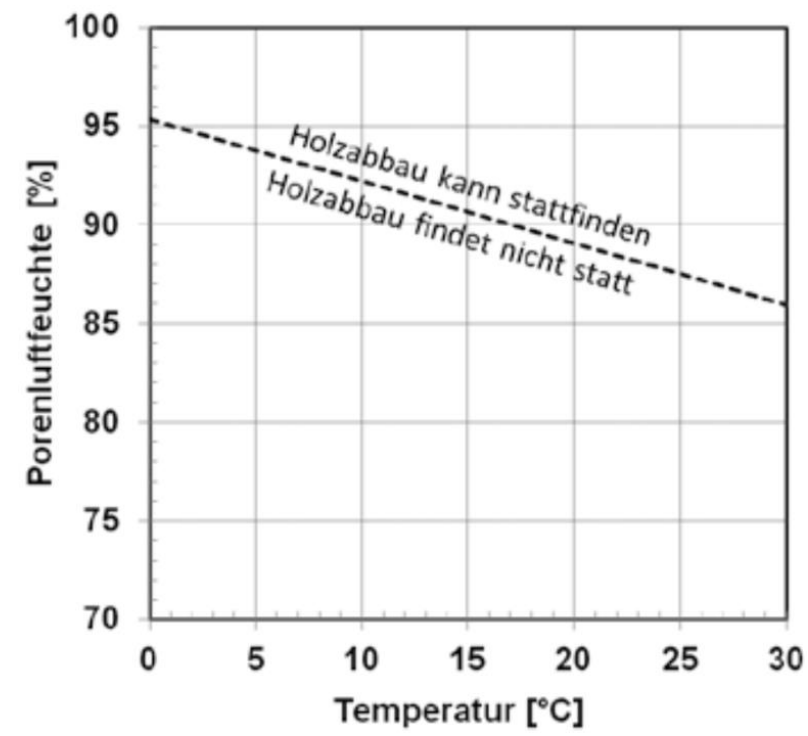

Fig. 2 Wood decay indicator WTA-Merkblad 6-8-15 [14]

\subsection{Mould growth at the interior surface}

The third criterion, mould growth at the interior surface, is indicated by the mould index, calculated based on the updated VTT model [15]-[18]. The VTT model is a mould prediction model which indicates the severity of mould in an index between 0 and 6 , developed by Hukka and Viitanen [19] based on the relative humidity and temperature of the interior surface. For defining the mould index, the interior plaster was assumed to be medium resistant; $\mathrm{k} 1=0.072$ (if $\mathrm{M}<1$ ), $\mathrm{k} 1=0.097$ (if $\mathrm{M} \geq 1), \mathrm{A}=0, \mathrm{~B}=5, \mathrm{C}=1.5$ and $\varphi_{\min }=85 \%$. The decline class "Almost no decline" $\left(\mathrm{C}_{\mathrm{eff}}=0.1\right)$ is assumed [20].

\section{Clustering of historic bricks}

The hygrothermal behavior of porous media is mainly defined by the moisture storage curve (MRC) and the moisture transport curve (LCC) of the materials. As both curves are linked to each other sampling curves from measured data individually to generate synthetic materials would not make any physical sense. Therefore an anternative method is used. 17 historic bricks from the IBK database which are fully caracterized are clusterder into four material clusters in accordance to the clustering process presented by Zhao J. [7]. Ward's method is used which means that a fusion of clusters is searched where the sum of the squared distances between the cluster's centroid is as little as possible. The centroid of a cluster is the average of each of the parameters (material properties) from the materials which are in the cluster. The dendrogram in Fig. 3 represents how the clusters between the 17 bricks are gradually formed.

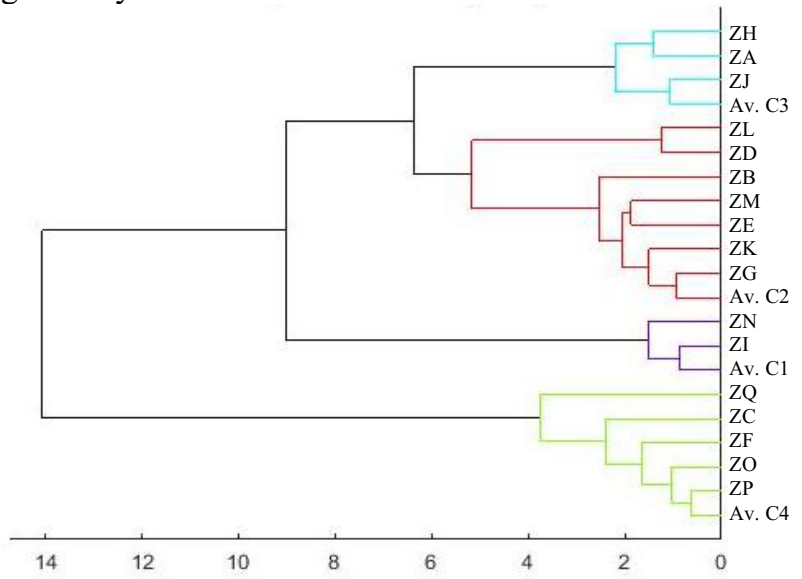

Fig. 3 Dendrogram based on Ward's method to cluster the 17 historic brick from the IBK database in 4 clusters. The synthetic average materials of each cluster are included as Av. $\mathrm{C} 1 \rightarrow 4$

The bricks clustered together as similar ones are then averaged to obtain a representative material (Av. $\mathrm{C} 1 \rightarrow 4)$. This is done for each of their material properties. Averaging of the MRC as LCC curves has to be done carefully to assure that during the averaging no data get lost in the crucial steep zones of the MRC (Figure 4). Mind that $\mathrm{pC}$ represents the logarithmic capillary pressure.

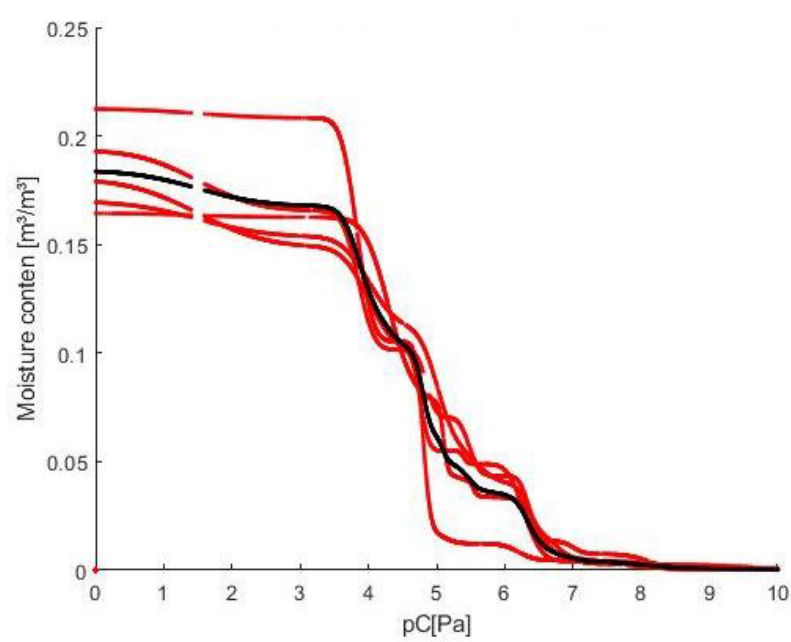

Fig. 4 Clustering the MRC of four similar bricks (red) into one generic material (Cluster 4, black) 
By normalizing the MRC and LCC of the four generic materials clusters the $\mathrm{nMRC}$ and $\mathrm{nLCC}$ in Fig. 5 are obtained representing reasonable varieties in the trend of both curves for historic bricks.

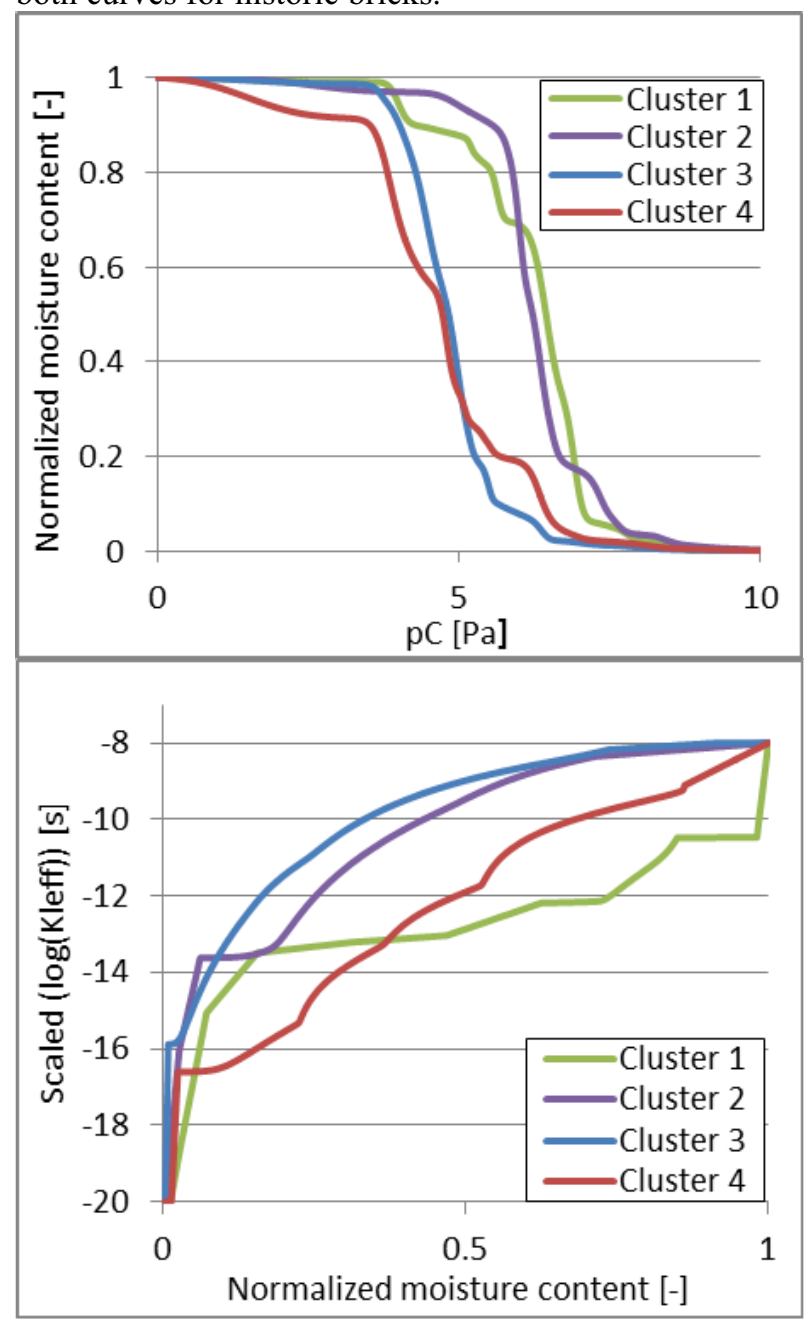

Fig. $5 \mathrm{nMRC}$ (top) and $\mathrm{nLCC}$ (bottom) for each of the four brick clusters for a normalized moisture content and a scaled logarithmic liquid conductivity of -8 as upper limit.

\section{Generating synthetic materials representing practice}

Matlab is used to produce repetitive input files for the HAM simulation model. Each simulation is performed for 3 years, to avoid an effect of the initial conditions only the third year is evaluated as output. Based on Table 1 physically realistic input values for historic masonry constructions are sampled for each of the input parameters. Including the predefined correlations between the material files. The sampled categorical parameter brick type (1 to 4 ) defines the assumed nMRC and nLCC curves, respectively of cluster 1 to 4 (Fig. 5). Based on the sampled absorption coefficient $\left(\mathrm{A}_{\mathrm{w}}\right)$ and the effective moisture content $\left(\vartheta_{\text {eff }}\right)$ of the simulation these curves are scaled to complete the hygrothermal properties of the assumed homogeneous bricks in the simulations. The conversion from $A_{w}$ to the liquid conductivity at effective saturation $\left(\mathrm{K}_{\mathrm{l}}\right.$, eff $)$ is based on Eq. 1, where $\mathrm{k}$ is a material dependent fitting parameter which is assumed as an average of the k-values of the materials present in that specific cluster (Fig. 3) in accordance to the clustering principle.

$$
\mathrm{K}_{\mathrm{l}, \mathrm{eff}}=\mathrm{k}^{*}\left(\left(\mathrm{~A}_{\mathrm{w}}\right)^{2} / \vartheta_{\mathrm{eff}}\right)
$$

\section{Sensitivity analysis}

Multiple statistical methods were investigated to gain insight in de dependency of output data (the damage indicators) in perspective to the input parameters ranging from scatter plots, to spearman rank correlation coefficients, and variance-based methods. Finally it was -in accordance with other authors [21] - concluded that Sobol Indices are the most reliable method to use to gain general insights as these indices can handle nonmonotonous correlations and multiple order effects between in- and output. The main drawback of Sobol Indices is that many simulations are required. To overcome this problem the SUMO (Surrogate MOdeling) tool [22] of Ghent University is used to generate a Kriging based surrogate model. This model generates 12 (the number of variable parameters in Table 1) dimensional surfaces that define the correlation of the input variables in perspective to a damage criteria. Fig. 6 shows the correlation between FTC and the rain exposure coefficient and orientation. A clear sinusoidal impact of the orientation is found with the highest risk at a $225^{\circ}$ South-West orientation as expected for the maritime climate of Western Europe.

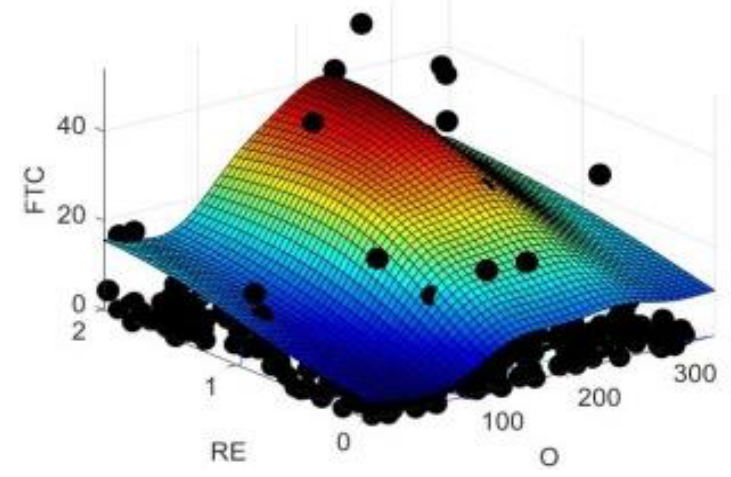

Fig. 6 Kriging based surface indicating the number of FTC in correlation with the orientation and rain exposure coefficient for brick type 4 and exterior climate Essen. The other 8 variable parameters are for this specific surface fixed at their average value to allow a $3 \mathrm{D}$ representation. The black dots are representing all 500 simulations performed to define the surrogate model.

Based on these surrogate models Total Sobol indices can be defined which indicate the dependency of the output on each of the input parameters (Fig. 7). Off course the representation of the actual HAM model compared to the surrogate model introduces a bias which is encountered by repeating the simulations three times; respectively A, $\mathrm{B}$ and $\mathrm{C}$. To generate the surrogate model three times 500 different simulations are performed and a fivefold cross validation is applied. Fivefold cross validation means that the number of simulations, in this case 500 , is split five times into two groups. One group for training 
the model and one for validation. By averaging the five models the fivefold cross validated model is found. This method allows to optimally use the available original data. To confirm the consistency of these results as well a separate validation set of 500 simulations is used to validate the results of a model trained based on 500 original simulations (VD). Similar results are found (Fig. 7). Also, when the results between the Kriging based surrogate surface and new original HAM is compared a generally good agreement is found but there are outliers which currently hamper a full replacement of HAM models with surrogate models.

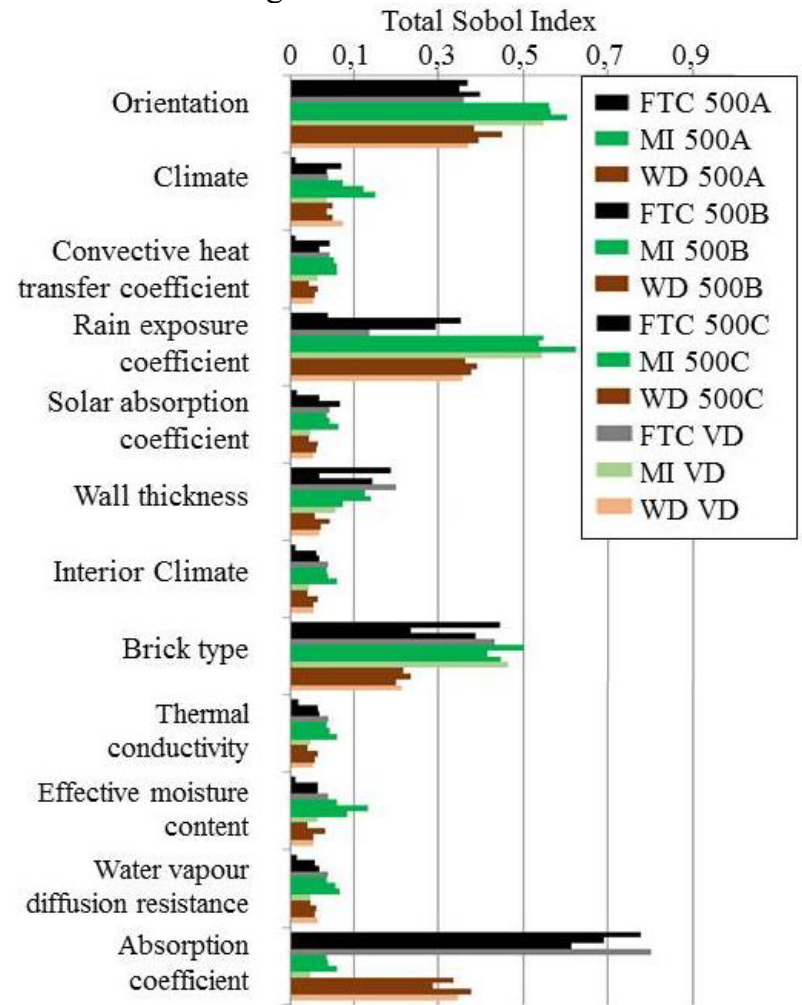

Fig. 7 Total Sobol indices defined for Kriging surrogate models trained for 3 different sets of 500 simulations validated with 5 fold cross validation (A,B and C) and 1 set of 500 simulations validated with another set of 500 simulations(VD).
The Total Sobol indices derived from the surrogate model indicate that for each of the damage criteria in general the rain exposure, represented by the orientation and rain exposure coefficient, and the brick type are dominant. In case of FTC and WD as well the absorption coefficient tends to be significant. Sobol indices are always positive thus a high number indicates a high dependency which does not mean a high risk. For example, a low $A_{w}$ induces high risks related to frost. The fact that the brick type is a dominant impact parameter indicates how important it is to develop highly detailed material databases and to avoid drawing conclusions without detailed material characterisation. The climate is indicated by the Total Sobol Indices as of lesser importance, as the difference between the three TRYs is considerably smaller than for example the impact of a doubling the rain intensity by means of the rain exposure coefficient.

\section{Classification trees}

The Total Sobol indices give insight in how important in general each of the input parameters is for realistic variations. But does this mean that the variation on the parameters, indicated as generally less important, can be neglected? No, the Poisson based classification tree (Figure 8) can clarify this. These trees are mathematically configured by splitting the batch of simulations, in this case 2000, into two separate groups based on the input variable that induces most of the heterogeneity on the output criterion. By repeating this process for the subgroups, a tree shaped figure is generated. For example, in Figure 8 the first split is performed based on the orientation, the simulations performed for an orientation of below or above $181.5^{\circ}$. The average output of the final subgroups indicates the potential risk for this combination of ranges of the input parameters (See Table in Figure 8). Note that the most important input parameters indicated by the Total Sobol indices in Figure 7 appear at the top in Figure 8, due to

\begin{tabular}{|c|c|c|}
\hline Split & $\begin{array}{c}\text { Sum FTC/ } \\
\text { Total } \\
\text { simulations }\end{array}$ & $\begin{array}{c}\text { Average } \\
\text { FTC }\end{array}$ \\
\hline 1 & $7138 / 2000$ & 3,571 \\
\hline 2 & $949 / 1016$ & 0,935 \\
\hline 3 & $6189 / 983$ & 6,295 \\
\hline 4 & $927 / 481$ & 1,928 \\
\hline 5 & $2003 / 661$ & 3,030 \\
\hline 6 & $4186 / 322$ & 12,990 \\
\hline 7 & $403 / 381$ & 1,060 \\
\hline 8 & $542 / 100$ & 5,235 \\
\hline 9 & $311 / 335$ & 0,931 \\
\hline 10 & $1692 / 326$ & 5,189 \\
\hline 11 & $1243 / 155$ & 8,011 \\
\hline 12 & $2943 / 167$ & 17,600 \\
\hline 13 & $369 / 202$ & 1,829 \\
\hline 14 & $471 / 192$ & 2,455 \\
\hline 15 & $1221 / 134$ & 9,100 \\
\hline
\end{tabular}

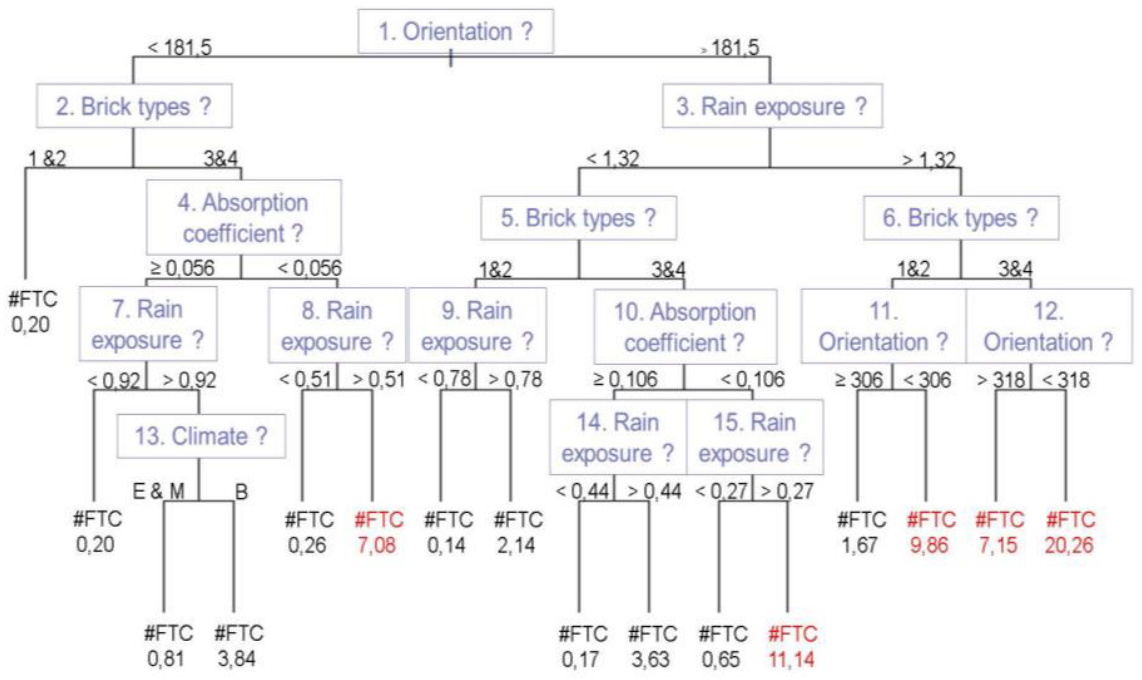

Fig. 8 Poisson based binary classification tree for FTC 
their high impact they show up first as separating parameters. Figure 8 indicates that for rather high absorptive bricks, of BT3 or 4 , with an orientation below $181,5^{\circ}$ and an above normal rain exposure the number of FTC is more than four times higher in Bremerhaven then in Essen or Munich. Off course these results highly depend on the input ranges assumed reasonable by the researcher. This indicates that this methodology has great potential but has to be applied carefully, to gain insights but should not to be used as decision tool for specific cases. Another application could be to apply this method to the difference in a damage indicator for the pre and post renovation cases. A classification tree of this difference could then indicate in which circumstances insulation increases damage risks significantly.

\section{Conclusions}

HAM models are computationally expensive and therefore in practice probabilistic simulations are not readily feasible. Unfortunately, because HAM simulations on historic masonries have multiple uncertainties which could be evaluated this way. Therefore, this study performs a sensitivity analysis on the most important impact factors that affect the durability of the construction, evaluated based on the number of critical Freeze-Thaw Cycles (FTC), Mould Growth (MG) and rotting of Wooden Beam head (WD) embedded in the masonry construction.

Based on probabilistic simulations, and a Kriging based surrogate model it was found that for each of the damage criteria as well the Rain intensity as the trend of the MRC and LCC are significant impact parameters. This indicates that more focus on accurately defining and open source sharing of these curves is required. The absorption coefficient has significance for the FTC and WD criterion. This way the surrogate model generates general insights in the impact of uncertainties in the input of hygrothermal modelling of masonry constructions. The major drawback of the surrogate modelling technique is that the current Kriging based model is not reliable enough for specific cases studies. Another interesting tool to allowquick preliminary insights was presented in this paper. Classification trees allow to highlight which parameters are potentially important for a specific condition. These clasification trees are rather easy to read and allow to gain preliminary insights for a specific case study without the use of HAM models.

\section{References}

1. C.-E. Hagentoft, A. Kalagasidis, B. Adl-Zarrabi, S. Roels, J. Carmeliet, and H. Hens, J. Therm. Envel. Build. Sci., 27, 4, 327-352, (2004).

2. J. G. Carl-Eric Hagentoft, Nuno M. M. Ramos, N. M. M. Ramos, and J. Grunewald, Annex 55, (2015).

3. F. A. H. H. Hens, C. Rode, T. Ojanen, Annex 24, (2002).
4. H. Janssen, B. Blocken, and J. Carmeliet, Int. J. Heat Mass Transf., 50, 5-6, 1128-1140, (2007).

5. EN 1991-1-4:2005+A 1, (2010).

6. $\quad$ EN 15026, (2007).

7. J. Zhao, R. Plagge, N. M. Ramos, M. L. Simões, and J. Grunewald, J. Build. Phys., 39, 2, 124146, (2015).

8. P. Mensinga, J. Straube, and C. Schumacher, Proc. Performances Envel. Whole Build. XI, 1-8, (2010).

9. D. Guilbert, S. Caluwaerts, K. Calle, N. Van Den Bossche, C. Veerle, and T. De Kock, Sci. Total Environ., 677, 10, 9-18, (2019).

10. E. Vereecken and S. Roels, Build. Environ., 148, October 2018, 524-534, (2019).

11. P. Kopecký, K. Staněk, M. Bureš, J. Richter, and J. Tywoniak, Energy Procedia, 132, 682-687, (2017).

12. U. Ruisinger, 2nd Cent. Eur. Symp. Build. Phys., September, 313-319, (2013).

13. M. Harrestrup and S. Svendsen, Build. Environ., 99, 59-72, (2016).

14. D. Kehl, Im Blickpunkt: Dächer bauphysikalisch richtig, 24, 2013.

15. E. Vereecken and S. Roels, Build. Environ., 51, 296-310, (2012).

16. H. Viitanen and T. Ojanen, Build. $x, 1-8,(2007)$.

17. T. Ojanen, K. Lähdesmäki, J. Vinha, and K. Salminen, Nord. Symp. Build. Phys., 2, (2011).

18. T. Ojanen, H. Viitanen, R. Peuhkuri, K. Lähdesmäki, J. Vinha, and K. Salminen, Therm. Perform. Exter. Envel. Build. XI, (2010).

19. A. Hukka and H. A. Viitanen, Wood Sci. Technol., 33, 6, 475-485, (1999).

20. E. Vereecken and S. Roels, Build. Environ., 51, 296-310, (2012).

21. T. Hou, D. Nuyens, S. Roels, and H. Janssen, Reliab. Eng. Syst. Saf., (2018).

22. D. Gorissen, K. Crombecq, I. Couckuyt, T. Dhaene, and P. Demeester, J. Mach. Learn., Vol. 11, 2051-2055. 